\title{
APLIKASI E-COMMERCE KASET ONLINE BERBASIS WEBSITE
}

\section{ONLINE CASSETTE E-COMMERCE APPLICATION BASED ON WEBSITE}

\author{
Lydia Liliana $^{1)^{*}}$, Yuliawan Krishartanto ${ }^{2)}$, Delly Vera ${ }^{3)}$ \\ ${ }^{1,2,3)}$ Program Studi Sistem Informasi, Universitas Bunda Mulia, Jakarta
}

Diterima 16 Maret 2021 / Disetujui 22 Maret 2021

\begin{abstract}
The rapid development of information technology certainly supports the application of e-commerce systems in product sales. At present, business people buying and selling cassette tapes or films that sell their cassettes physically are still mushrooming. Rapidly developing internet technology makes it easy for people to make purchases through the website. From the buyer side, making online purchases can save time and costs, while from the business side, of course they will be facilitated in controlling the stock of tapes, providing cassette information in more detail to control ordering of stock of goods. Therefore, the author decides to create an online cassette e-commerce website in order to speed up the transaction process for ordering cassettes. The method used in making e-commerce websites buying and selling tapes online is the System Development Life Cycle (SDLC) with a waterfall model consisting of Requirement Analysis, Design, Coding, Testing and Implementation. With this application, the results obtained are expected to make it easier for the public to conduct online cassette purchase transactions and provide an accurate reporting system for business people buying and selling cassettes online.
\end{abstract}

Keywords: Website, E-commerce, Cassette

\begin{abstract}
ABSTRAK
Perkembangan teknologi informasi yang semakin pesat tentunya mendukung penerapan sistem $e$ commere dalam penjualan produk. Saat ini, pelaku usaha bisnis jual beli kaset lagu ataupun film yang menjual kasetnya secara fisik masih terus menjamur. Teknologi internet yang berkembang pesat membawa kemudahan bagi masyarakat untuk melakukan pembelian barang melalui website. Dari sisi pembeli, melakukan transaksi pembelian secara online dapat menghemat waktu dan biaya, sedangkan dari sisi pelaku bisnis, tentunya mereka akan dimudahkan dalam melakukan pengontrolan stok kaset, memberikan informasi kaset secara lebih detail hingga mengontrol pemesanan stok barang. Oleh karena itu, penulis memutuskan untuk membuat website ecommerce kaset online agar dapat mempercepat proses transaksi pemesanan kaset. Metode yang digunakan dalam pembuatan website e-commerce jual beli kaset online ini adalah System Development Life Cycle (SDLC) dengan model waterfall yang terdiri dari Requirement Analysis, Design, Coding, Testing dan Implementation. Dengan adanya aplikasi ini, hasil yang didapatkan diharapkan dapat memudahkan masyarakat dalam melakukan transaksi pembelian kaset online dan menyediakan sistem pelaporan yang akurat bagi para pelaku usaha bisnis jual beli kaset online.
\end{abstract}

Kata Kunci: Website, E-commerce, Kaset

\footnotetext{
*Korespondensi Penulis:

E-mail: 1ydialiliana6@gmail.com
} 


\section{PENDAHULUAN}

E-commerce mempunyai peran penting dalam teknologi informasi, oleh karean itu maka teknologi hendaknya dapat digunakan untuk membantu permasalahan dalam kehidupan manusia, dalam hal ini adalah peran di bidang penjualan kaset secara online.

Permasalahan utama yang dihadapi oleh para pelaku bisnis jual beli kaset online adalah tidak adanya sistem yang terintegrasi untuk proses penjualan, pembelian, pemasukan dan pengeluaran barang, monitoring, pencatatan transaksi permintaan barang kepada pemasok, pencatatan transaksi penjualan hingga reporting. Jika dilihat dari sisi pembeli, untuk membeli kaset mereka harus mendatangi toko fisik yang tentunya membutuhkan biaya dan waktu. Kemudian, apabila kaset yang dibeli cacat/rusak, pembeli seringkali disulitkan dalam melakukan komplain.

Berdasarkan latar belakang diatas, dibuatlah website e-commerce yang bertujuann untuk memudahkan customer dalam melakukan pemesanan kaset secara online baik untuk barang ready stock ataupun pre-order dengan proses pengiriman menggunakan jasa pihak ketiga, yang dimana customer membayar ongkos kirim untuk pengiriman barang tersebut. Selain itu, customer akan dimudahkan dalam melakukan komplain apabila barang yang diterima tidak sesuai. Bagi pelaku bisnis, website ini akan menampilkan fungsi pelaporan (Reporting) mengenai penjualan dan pembelian kaset serta pemasukan dan pengeluaran kaset.

Penelitian terdahulu yaitu "Perancangan Sistem Informasi Rental VCD/DVD Berbasis Web di Redboxz Maguwoharjo Sleman Yogyakarta" oleh Ardhana, Mirza Hendrawan dan Anggit Dwi Hartanto membahas proses rental VCD/DVD berbasis website (Ardhana, 2016). Hal yang melatarbelakangi pembuatannya ialah karena saat ini pemesanan online sedang menjadi salah satu trend untuk pelaku usaha demi memenuhi kebutuhan pelanggan secara cepat dan efisien.

Berdasarkan inspirasi yang telah dijabarkan di atas, penulis membuat website yang memberikan manfaat berupa kemudahan kepada customer dalam mencari dan memesan kaset. Bukan hanya membantu customer, website ini membantu pelaku bisnis jual beli kaset mengelola report penjualan, pembelian, komplain hingga stok.

\section{TINJAUAN PUSTAKA}

\section{A. Sistem Informasi}

Sistem Informasi adalah kumpulan atau susunan yang terdiri dari hardware dan software serta tenaga pelaksanaannya yang bekerja dalam sebuah proses berurutan dan secara bersama-sama saling mendukung untuk menghasilkan suatu produk (Asmara, 2016). Sistem informasi merujuk kepada interaksi antara orang, proses algoritmik, data, dan teknologi (Prabowo, 2017).

\section{B. E-commerce}

E-commerce adalah proses membeli dan menjual atau tukar menukar produk, jasa atau informasi melalui komputer (Sulthoni, 2016). E-commerce merupakan suatu proses membeli dan menjual produk secara elektronik yang dilakukan oleh konsumen dengan menggunakan media world wide web (WWW) internet (Maulana et al., 2016).

\section{Website}

Website adalah salah satu aplikasi yang berisi dokumen-dokumen multimedia (Teks, gambar, suara, animasi, video) yang mengunakan protokol HTTP (Hypertext Transfer Protokol) (Hasugian, 2018). Website dapat bersifat statis dan dinamis. Bersifat statis apabila isi informasi website tetap dan jarang berubah, sedangkan bersifat dinamis apabila isi informasi website selalu berubah-ubah (Riyadi et al., 2017). 


\section{METODE PENELITIAN}

Berikut ini adalah tahapan penelitian yang dilakukan dalam proses pembuatan website:

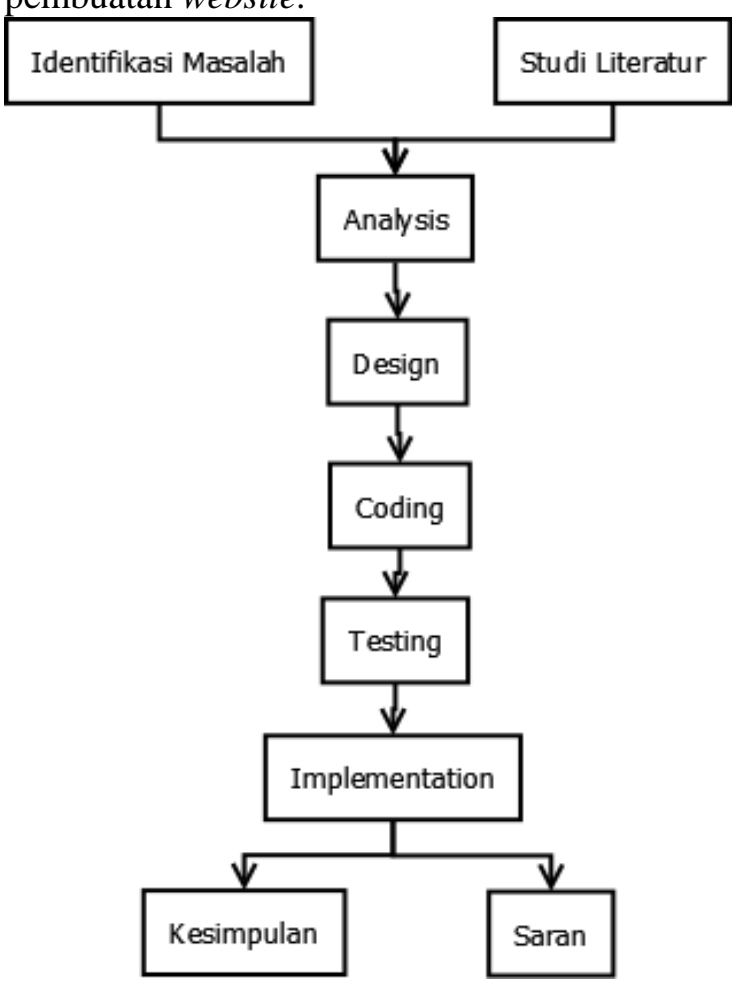

Gambar 1. Tahapan Penelitian

(Shabrina et al., 2018), (Dari, 2015)

Berdasarkan gambar 1, diketahui bahwa penelitian ini dimulai dari (Aslamah, 2015), (Istifani \& Sholiq, 2017),

1. Identifikasi Masalah, menganalisa permasalahan yang terjadi pada proses bisnis berjalan.

2. Studi Literatur, digunakan sebagai landasan teori dalam penyelesaian masalah secara ilmiah. Setelah topik ditentukan kemudian dilakukan studi literatur yang dapat menunjang pengerjaan penelitian. Dalam tahap ini digunakan jurnal dari penelitian terdahulu.

3. Analysis, dilakukan pengumpulan kebutuhan sistem informasi untuk menspesifikasikan kebutuhan sistem yang dibutuhkan oleh user. Pengumpulan kebutuhan berupa data input, proses yang terjadi, serta output yang dihasilkan.

4. Design, pada tahap ini kebutuhankebutuhan yang terdapat di sistem diterjemahkan yang berasal dari tahap Analysis agar dapat diimplementasikan menjadi program di tahap selanjutnya, sehingga dilakukan pembuatan design database dan user interface.

5. Coding, sistem akan diimplementasikan dalam bentuk source code yang dibuat menjadi beberapa modul. Modul-modul tersebut dikelompokkan berdasarkan metode untuk memudahkan proses pengembangan dan mencegah terjadinya kebingungan dalam proses pembuatan.

6. Testing, seluruh modul yang dikembangkan dalam tahap coding dilakukan pengujian untuk mengecek setiap kesalahan atau kegagalan dalam pembuatan website.

7. Implementation, tahap ini mengintegrasikan sumber daya fisik yang menghasilkan suatu sistem yang bekerja.

8. Kesimpulan dan Saran, merupakan tahapan akhir yang dilakukan setelah perancangan website telah selesai dilakukan (Firmansyah \& Pitriani, 2017), (Tabrani \& Pudjiarti, 2017), (Wahyudi, 2018).

\section{HASIL DAN PEMBAHASAN}

Berikut ini adalah hasil analisa dari pembuatan website.

\section{A. Analysis}

Pada tahap ini, dibuat DFD level 0 pada website jual beli kaset online. 


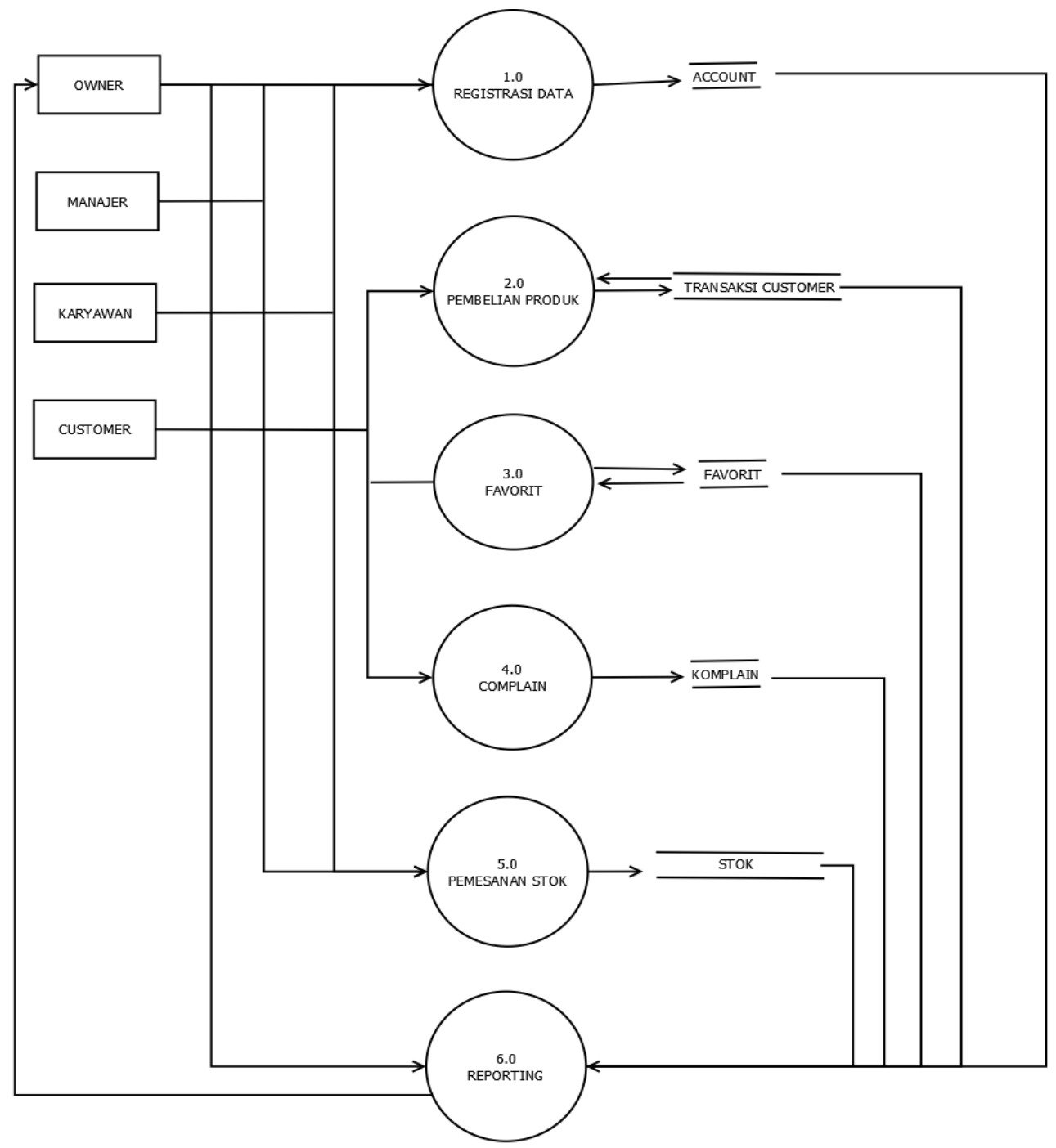

Gambar 2. DFD Level 0

Berdasarkan gambar 2, menunjukkan bahwa masing-masing user (Owner, Manajer, Karyawan dan Customer) akan memberikan input yang berbeda-beda. Proses yang dilakukan oleh setiap user adalah sebagai berikut:

1. Owner dapat melakukan registrasi data account serta melakukan registrasi data stok dari setiap proses yang dilakukan di website. Hasil registrasi data account akan masuk ke data stores account dan hasil registrasi data stok akan masuk ke data stores stok. Owner merupakan pelaku utama yang dimana keseluruhan laporan akan diberikan akses kepada owner.

2. Manajer dapat melakukan registrasi data account, pemesanan stok dan mengakses report dari setiap proses yang dilakukan di website. Hasil registrasi data account akan masuk ke data stores account, hasil registrasi data stok akan masuk ke data stores stok, dan hasil pemesanan stok akan masuk ke data stores transaksi stok. Proses pembelian stok dilakukan oleh karyawan dan manajer, dimana manajer bertugas untuk menambahkan supplier dan karyawan melakukan pemesanan barang, lalu manajer akan mengkonfirmasinya. 
3. Karyawan dapat melakukan registrasi account serta melakukan registrasi data stok barang. Selain itu, karyawan dapat melakukan pemesanan stok. Hasil registrasi data account akan masuk ke data stores account, hasil registrasi data stok akan masuk ke data stores stok dan hasil pemesanan stok akan masuk ke data stores transaksi stok.

4. Customer dapat melakukan pembelian produk, favorit produk, dan komplain terhadap barang yang dibeli. Hasil pembelian produk akan masuk ke data stores transaksi customer, hasil favorit barang akan masuk ke data stores favorit dan hasil komplain customer akan masuk ke data stores komplain. Komplain yang diinputkan oleh customer akan dikonfirmasi dan ditanggapi oleh karyawan.

\section{B. Design}

Pada tahap ini dilakukan normalisasi pada database. Berikut ini adalah hasil normalisasi pada e-commerce kaset online.

- UNF

Berikut ini adalah hasil dari UNF:

$>$ type_account_name

$>$ account_name

$>$ account_birth

$>$ account_sex

$>$ account_add

$>$ account_email

$>$ account_phone

$>$ account_password

$>$ stock_name

$>$ stock_kategori

$>$ stock_type

$>$ stock_negara

$>$ stock_jumlah

$>$ stock_harga

$>$ stock_photo

$>$ stock_detail

$>$ stock_status

$>$ supplier_tanggal

$>$ supplier_jumlah

$>$ supplier_status

$>$ stock_jml_beli

$>$ stock_hrgtotal

$>$ cart_address

$>$ cart_ttlhrg

$>$ payment_status
$>$ cart_date

$>$ namarekbank

$>$ fotobukti

$>$ confirmator

$>$ komplain_isi

$>$ komplain_status

$>$ komplain_tanggal

$>$ wishlist

Bentuk UNF atau bentuk tidak normal (Unnormalized Form) di mana relasi dirancang tanpa memperhatikan tipe data yang sejenis, dapat dilihat dari tabel tersebut penyusunan tiap atribut data masih berantakan dan tidak beraturan. Bentuk UNF tidak dianjurkan atau harus dihindari dalam perancangan database karena dapat menyebabkan terjadinya anomali data.

- $1 \mathrm{NF}$

Pada bentuk 1NF, sudah mengidentifikasi primary key. Terdapat 4 tabel yang terbentuk pada tahap $1 \mathrm{NF}$, antara lain sebagai berikut:

Bentuk 1NF dari tabel cart, yang terdiri dari:

$$
\begin{aligned}
& >\text { cart_id(Primary Key) } \\
& >\text { account_id } \\
& >\text { cart_address } \\
& >\text { cart_ttlhrg } \\
& >\text { cart_date } \\
& >\text { payment_status } \\
& >\text { namarekbank } \\
& >\text { fotobukti } \\
& >\text { confirmation } \\
& >\text { wishlist }
\end{aligned}
$$

Bentuk 1NF dari tabel account, yang terdiri dari:
$>$ account_id (Primary Key)
$>$ type_account_name
$>$ account_name
$>$ account_birth
$>$ account_sex
$>$ account_add
$>$ account_email
$>$ account_phone
$>$ account_password

Bentuk 1NF dari tabel stock, yang terdiri dari:
$>$ stock_id (Primary Key)
$>$ stock_name 
stock_kategori

$>$ stock_type

$>$ stock_negara

$>$ stock_jumlah

$>$ stock_harga

$>$ stock_photo

$>$ stock_detail

$>$ stock_status

$>$ supplier_id

$>$ supplier_tanggal

$>$ supplier_jumlah

$>$ supplier_status

Bentuk 1NF dari tabel komplain, yang terdiri dari:

$>$ komplain_id

$>$ account_id

$>$ cart_id

$>$ stock_id

$>$ komplain_isi

$>$ komplain_status

$>$ komplain_tanggal

Bentuk 1NF tersebut dibuat untuk mengelompokkan data sehingga anomali data dapat diatasi, contoh saat melakukan fungsi CRUD data stock, maka tidak bersinggungan dengan data komplain.

- $2 \mathrm{NF}$

Fungsi normalisasi 2NF untuk menghapus beberapa subset data yang ada pada tabel dan menempatkan mereka pada tabel terpisah untuk mencegah terjadinya anomali data dalam melakukan fungsi CRUD, serta data yang tersimpan memiliki integritas/dapat dipercaya akurasinya.

Bentuk 2NF dari tabel Type Account, terdiri dari: type_account_id dan type_account_name

Pada awalnya type_account_name tergabung pada tabel account, pada normalisasi $2 \mathrm{NF}$ membentuk tabel sendiri dan dapat memunculkan atribut baru type_account_id. Atribut type_account_id diperlukan karena terdapat 4 tipe user yang berbeda dalam website ini yaitu Owner, Manajer, Karyawan dan Customer yang dimana masing-masing user mempunyai akses yang berbedabeda.
Tabel 1. 2NF Tabel Account

\begin{tabular}{|c|}
\hline account_id \\
\hline type_account_id \\
\hline account_name \\
\hline account_birth \\
\hline account_sex \\
\hline account_add \\
\hline account_email \\
\hline account_phone \\
\hline account_password \\
\hline
\end{tabular}

Pada tabel 1, type_account_id merupakan foreign key. Atribut type_account_id menentukan account_id sehingga dapat dikatakan sebagai ketergantungan fungsional, karena tipe account user baik sebagai owner ataupun customer mempengaruhi account_id.

Tabel 2. 2NF Tabel Stock

\begin{tabular}{|c|}
\hline stock_id \\
\hline stock_name \\
\hline stock_kategori \\
\hline stock_type \\
\hline stock_negara \\
\hline stock_jumlah \\
\hline stock_harga \\
\hline stock_photo \\
\hline stock_detail \\
\hline stock_status \\
\hline supplier_id \\
\hline
\end{tabular}

Pada tabel 2, memisahkan atribut supplier_tanggal, supplier_jumlah dan supplier_status lalu dibuat dalam bentuk tabel baru, dikarenakan apabila user menambahkan data stok barang, maka harus menambahkan detail supplier yang mendistribusikan stok tersebut. 


\section{Tabel 3. 2NF Tabel Cart}

\begin{tabular}{|c|}
\hline cart_id \\
\hline account_id \\
\hline cart_address \\
\hline cart_ttlhrg \\
\hline payment_status \\
\hline cart_date \\
\hline Namarekbank \\
\hline Fotobukti \\
\hline Confirmator \\
\hline
\end{tabular}

Pada tabel 3, normalisasi 2NF juga menciptakan hubungan antar tabel baru dan tabel lama dengan menciptakan foreign key. Pada tabel ini, account_id merupakan foreign key. Atribut account_id menentukan cart_id sehingga dapat dikatakan sebagai ketergantungan fungsional, karena ID account akan menentukan id pembelanjaan customer itu sendiri.

\section{Tabel 4. 2NF Tabel Detail Cart}

\begin{tabular}{|c|}
\hline Nomor \\
\hline cart_id \\
\hline stock_id \\
\hline stock_hrgsatuan \\
\hline stock_jml \\
\hline stock_hrgtotal \\
\hline
\end{tabular}

Pada tabel 4, terdapat ketergantungan transitif yang dimana merupakan ketergantungan secara fungsional suatu atribut kepada atribut lainnya melalui atribut yang lain pula. Pada tabel ini cart_id bergantung pada nomor dan nomor bergantung pada stock_id. Sehingga, dapat dinotasikan cart_id $\Rightarrow$ nomor $\Rightarrow$ stock_id.

Bentuk 2NF dari tabel komplain, yang terdiri dari:

- komplain_id (Primary Key)

- account_id

- cart_id

- stock_id

- komplain_isi

- komplain_status

- komplain_tanggal

Normalisasi 2NF juga menciptakan hubungan antar tabel baru dan tabel lama dengan menciptakan foreign key. Pada tabel ini, account_id, cart_id dan stock_id merupakan foreign key.

Bentuk 2NF dari tabel wishlist, yang terdiri dari:

- wishlist_id(Primary Key)

- account_id

- stock id

Pada tahap 2NF ini, terdapat ketergantungan transitif yang dimana merupakan ketergantungan secara fungsional suatu atribut kepada atribut lainnya melalui atribut yang lain pula. Pada tabel ini account_id bergantung pada wishlist_id dan wishlist_id bergantung pada stock_id. Sehingga, dapat dinotasikan account_id $=>$ wishlist_id $=>$ stock_id.

\section{Coding}

Pada proses pembuatan website jual beli kaset online, menggunakan bahasa pemrograman PHP ( Hypertext Preprocessor), Bootstrap, JQuery dan dikombinasikan dengan database MySQL.

\section{Testing}

Pada tahap testing, menggunakan black box testing yang merupakan bagian dari User Acceptance Testing ( UAT ). Berikut ini adalah salah satu modul UAT yang terdapat pada tabel 5 . 
Tabel 5. UAT Modul Account

\begin{tabular}{|c|c|c|c|c|c|}
\hline No & $\begin{array}{c}\text { Use } \\
\text { Case/Test } \\
\text { Case }\end{array}$ & Pre-Condition & Test Steps & $\begin{array}{l}\text { Expected } \\
\text { Results }\end{array}$ & Actual Result \\
\hline AC. 1 & $\begin{array}{c}\text { Navigation } \\
\text { Bar Left } \\
\text { Side }\end{array}$ & $\begin{array}{l}\text { 1. Login as Owner, } \\
\text { Manajer dan } \\
\text { Karyawan } \\
\text { 2. Isi navigation bar } \\
\text { left side akan } \\
\text { disesuaikan dengan } \\
\text { jenis akun yang } \\
\text { sedang login }\end{array}$ & $\begin{array}{l}\text { Pilih masing- } \\
\text { masing button } \\
\text { link yang ada } \\
\text { pada navigation } \\
\text { left bar di page } \\
\text { account } \\
\text { Owner/Manajer/ } \\
\text { Karyawan }\end{array}$ & $\begin{array}{l}\text { Masing- } \\
\text { masing link } \\
\text { berjalan } \\
\text { sesuai } \\
\text { dengan } \\
\text { fungsinya. }\end{array}$ & $\begin{array}{c}\text { Akan berubah } \\
\text { sesuai dengan jenis } \\
\text { akun yang masuk } \\
\text { seperti Owner, } \\
\text { Manajer, atau } \\
\text { Karyawan }\end{array}$ \\
\hline AC. 2 & $\begin{array}{c}\text { Navigation } \\
\text { Bar Top }\end{array}$ & $\begin{array}{l}\text { 1. Login as Owner, } \\
\text { Manajer dan } \\
\text { Karyawan } \\
\text { 2. Nama yang ada di } \\
\text { samping Hello } \\
\text { akan ditampilkan } \\
\text { sesuai dengan } \\
\text { nama pemilik akun } \\
\text { Owner, Manajer, } \\
\text { Karyawan yang } \\
\text { sedang login }\end{array}$ & $\begin{array}{l}\text { Pilih masing- } \\
\text { masing button } \\
\text { link yang ada } \\
\text { pada navigation } \\
\text { bar top }\end{array}$ & $\begin{array}{l}\text { Masing- } \\
\text { masing link } \\
\text { berjalan } \\
\text { sesuai } \\
\text { dengan } \\
\text { fungsinya. }\end{array}$ & $\begin{array}{l}\text { Terdapat nama dari } \\
\text { pengguna akun } \\
\text { Owner, Manajer } \\
\text { atau Karyawan } \\
\text { yang dijadikan } \\
\text { untuk menampung } \\
\text { menu tertentu. }\end{array}$ \\
\hline
\end{tabular}

\section{E. Implementation}

Berikut ini adalah tampilan halaman front end atau halaman beranda untuk customer yang terdapat pada gambar 3 dan tampilan halaman backend atau halaman dashboard untuk owner, manajer dan karyawan.
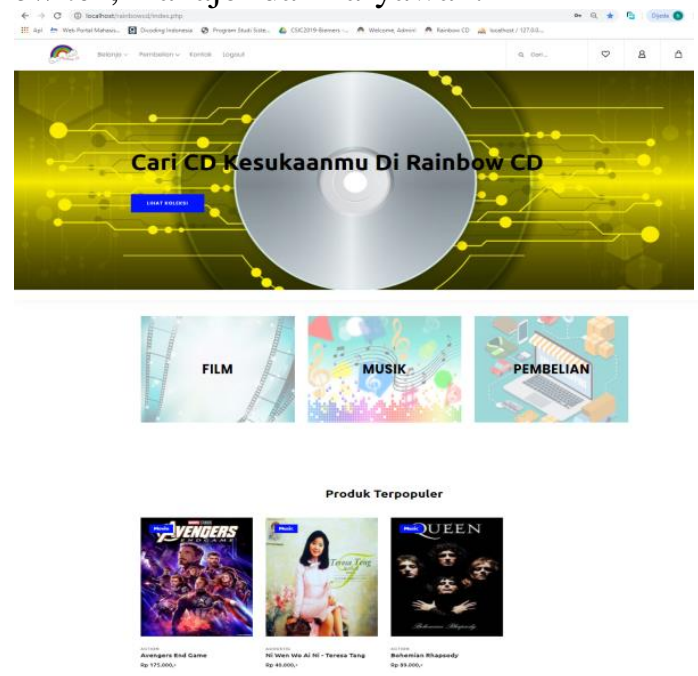

Gambar 3. Tampilan Halaman Utama Customer
Pada gambar 3, merupakan tampilan halaman utama yang dapat diakses oleh customer. Customer dapat mengakses halaman pembelian kaset, history pembelian kaset, halaman checkout, halaman profil, keranjang belanja, favorit dan melakukan komplain.

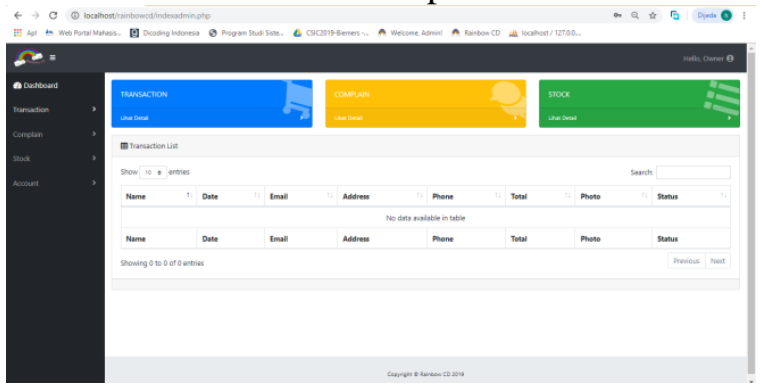

Gambar 4. Tampilan Halaman Owner, Manajer Karyawan

Pada gambar 4, merupakan tampilan halaman dashboard yang dapat diakses oleh owner, manajer dan karyawan. Terdapat 4 halaman yang dapat diakses, yaitu transaction, complain, stock dan account. Owner dapat mengakses semua halaman dan melihat reporting. Manajer dapat mengakses halaman transaction, complain dan stock, menambahkan 
Versi Online: http://journal.ubm.ac.id/index.php/jbase DOI: http://dx.doi.org/10.30813/jbase.v4i1.2732 data supplier, accept/reject permintaan stok dari karyawan serta melihat reporting. Karyawan dapat melihat transaksi, mengelola komplain, menambahkan data barang dan melihat laporan stok.

\section{KESIMPULAN}

Kesimpulan yang diperoleh setelah dibuatnya website jual beli kaset online ini antara lain:

1. Memudahkan masyarakat dalam melakukan transaksi pembelian kaset ready stock maupun pre-order tanpa harus mendatangi toko secara langsung.

2. Menyajikan laporan secara cepat, tepat dan akurat, yang meminimalisir kesalahan pelaporan secara manual.

3. Menyimpan setiap data-data transaksi yang pernah dilakukan.

\section{DAFTAR PUSTAKA}

Andry, J. F., Geasela, Y. M., Wailan, A., Matjik, B. A., Kurniawan, A., \& Junior, J. (2019). Penggunaan COBIT 4.1 Dengan Domain ME Pada Sistem Informasi Absensi (Studi Kasus: Universitas XYZ). Informatika Mulawarman: Jurnal Ilmiah Ilmu Komputer, $\quad 13(2), \quad 97$. https://doi.org/10.30872/jim.v13i2.1152

Ardhana, M. H. (2016). Perancangan Sistem Informasi Rental VCD/DVD Berbasis Web di RedBoxz Maguwoharjo Sleman Yogyakarta. Jurnal Teknik Informatika STMIK AMIKOM Yogyakarta, June, 3-6.

Aslamah. (2015). Perancangan E-Shop Penjualan Studi Kasus Toko Radal Smart. Jurnal Teknik Informatika, 53(9), 5-9.

Asmara, R. (2016). Sistem Informasi Pengolahan Data Penanggulangan Bencana Pada Kantor Badan Penanggulangan Bencana Derah (BPBD) Kabupaten Padang Pariaman. Jurnal J-Click, 3(2), 1-10.

Dari, W. (2015). Penerapan Metode System Development Life Cycle Pada Pembuatan Sistem Informasi Penjualan Produk Batik Kurowo Jakarta. Jurnal Khatulistiwa Informatika, 3(2), 222-228.

Firmansyah, Y., \& Pitriani. (2017). Penerapan
Metode SDLC Waterfall Dalam Pembuatan Aplikasi Pelayanan Anggota Pada CU Duta Usaha Bersama Pontianak. Jurnal Bianglala Informatika, 5(2), 53-61. https://ejournal.bsi.ac.id/ejurnal/index.php/ Bianglala/article/view/2703/1813

Hasugian, P. S. (2018). Perancangan Website Sebagai Media Promosi Dan Informasi. Journal Of Informatic Pelita Nusantara, $3(1), 82-86$.

Istifani, A. F., \& Sholiq. (2017). Rancang Bangun Aplikasi Koperasi Simpan Pinjam dengan Metode Viewpoint Oriented Requirement Definition. Jurnal Sisfo, 6(3), 149-165.

Maulana, S. M., Susilo, H., \& Riyadi. (2016). Implementasi E-Commerce Sebagai Media Penjualan Online (Studi Kasus Pada Toko Pastbrik Kota Malang). Jurnal Administrasi Bisnis, 29(1), 1-9.

Prabowo, D. W. I. (2017). Manfaat Sistem Informasi dan Pengaruh Sistem Informasi Bagi Perusahaan. Jurnal Sistem Informasi Management, 2-4.

Riyadi, A. S., Retnandi, E., \& Deddy, A. (2017). Perancangan Sistem Informasi Berbasis Website Subsistem Guru Sekolah Pesantren Persatuan Islam 99 Rancabango. Jurnal Algoritma, 9(40), 1-11.

Shabrina, E. R., Rusvita, I. Della, Riyandini, I. S., \& Rahayu, S. (2018). Sistem Aplikasi Layanan Untuk Mengakomodir Permintaan Terhadap Department Informasi Teknologi (Studi Kasus: PT. Aivon Mediatama). Jurnal Cendikia, XVI(Oktober), 84-88.

Sulthoni, A. (2016). Sistem Informasi ECommerce Pemasaran Hasil Pertanian Desa Kluwan Berbasis Web. Jurnal Sistem Informasi Sistem, 1-11.

Tabrani, M., \& Pudjiarti, E. (2017). Analisis Sistem Akuntansi Penggajian Dan Pengupahan Karyawan Dalam Upaya Mendukung Pengendalian Intern (Studi Pada PT Wonojati Wijoyo Kediri). Jurnal Inkofar, 1(2), 189-196.

Wahyudi, A. (2018). Perancangan Sistem Menggunakan Metode SDLC. Jurnal Dinamika Informatika, 4(2), 1-11. 
Versi Online: http://journal.ubm.ac.id/index.php/jbase DOI: http://dx.doi.org/10.30813/jbase.v4i1.2732

Hasil Penelitian
Journal of Business and Audit Information Systems Vol 4 (No.1) : 40-48. 2021 p-ISSN: 2615-6431 e-ISSN: 2620-7907 